\title{
BEHAVIOR OF GASTRIC CANCER IN BRAZILIAN POPULATION
}

\section{Comportamento do câncer gástrico na população brasileira}

\author{
Carlos Eduardo JACOB, Claudio BRESCIANI, Joaquim José GAMA-RODRIGUES, Osmar Kenji YAGI, \\ Donato MUCERINO, Bruno ZILBERSTEIN, Ivan CECCONELLO
}

ABCDDV/635

Jacob CE, Bresciani C, Gama-Rodrigues JJ, Yagi OK, Mucerino D, Zilberstein B, Cecconello I. Behavior of gastric cancer in brazilian population. ABCD Arq Bras Cir Dig 2009;22(1):29-32

ABSTRACT - Background - Gastric cancer (GC) is a predominately male disease. Usually for every female that suffers from this condition there are two males and occurred an increase in the number of females in last decades. Brazil is poor in data about this issue. Aim - To verify if in Brazil it happened: a) a change in the gender ratio and on the average age of the patients; b) an increase in the number of patients with 70 years of age or more suffering from this disease; c) changes in the gender ratio and in the average age in the several gastric locations during the period of study. Methods - The medical history of patients diagnosed with primary gastric adenocarcinoma, between 1971 and 1998 were obtained at Hospital das Clínicas of the University of São Paulo, São Paulo, SP, Brazil. Exclusion criteria were: patients suffering from a non epithelial gastric malignancy; adenocarcinoma from the intestinal metaplasia in the distal esophagus invading the proximal stomach and patients submitted to a gastric resection, due to a benign or malignant tumor during the last five years prior to the surgical procedure analyzed in this study. The patients were divided into 10 years age groups and also divided in three groups, according to their ages and time intervals. Interrelationships between gender and age, and with tumor's location on gastric wall were analyzed. Results - From 1971 to 1998, 1578 patients with GC were hospitalized. Among them, 1021 were treated with gastric resection, corresponding to $64.7 \%$ of all patients. There was an increase in the proportion of patients older than 70 years, and decrease between 41 and 70 years. There was no statistical significant difference among the average ages and the different locations. There were significant differences for the locations favoring proximal third and stump, both more prevalent in males. Conclusions - a) Occurred modifications in the ratio between genders: greater number of women and an increase in the number of male patients in the age group between 41 and 70 years; b) it was proved the greater number of occurrences in patients over 70 years of age; $c$ ) there was a greater increase in the male predominance in the tumors located in the stomach's proximal third.

HEADINGS - Gastric neoplasm. Epidemiology. Surgery.

\section{INTRODUCTION}

Every year we have been witnessing a decrease in the number of new cases of gastric cancer (GC) in many parts of the world, nevertheless, it still remains the second largest cancer killer.

In Brazil, estimates conducted in 2003 by The National Cancer Institute, displayed an incidence of 16,4 males and 7,38 females suffering from these type of cancer, for 100.000 inhabitants. It is estimated that there are 20,420 new cases of the disease and 11,070 deaths being the second most frequent cancer cause of death in the nation with 9,39\% (www.inca.org.br).

Gastric cancer is a predominately male disease. Usually for every female that suffers from this condition there are two males ${ }^{4}$. But, an increase in the number of females with GC is published in last decades ${ }^{9}$.

From the University of São Paulo School of Medicine, Department of Gastroenterology, Digestive Surgery Division, São Paulo, SP, Brasil

Correspondence: Ivan Cecconello, e-mail: cecconello@terra.com.br
In GC, this investigation intents to verify if happened: a) a change in the gender ratio and on the average age of the patients; b) an increase in the number of patients with 70 years of age or more suffering from this disease; c) changes in the gender ratio and in the average age in the several gastric locations during the period of study.

\section{METHODS}

The medical history of patients diagnosed with primary gastric adenocarcinoma, between 1971 and 1998 were obtained at Hospital das Clínicas of the University of São Paulo (HCFMUSP), São Paulo, SP, Brazil.

In choosing the individuals that would take part in this sample the following exclusion criteria were taken into account: patients suffering from a non epithelial gastric malignancy; adenocarcinoma from the intestinal metaplasia in the distal esophagus invading the proximal stomach and patients that were submitted to a gastric resection, due to a benign or malignant tumor during the last five years prior to the surgical procedure analyzed in this study. 
The patient's ages referred corresponded to the ones at the time they were diagnosed with the GC and also was marked the dates of the surgical resection.

The patients were divided into 10 years age groups and divided in three groups, according to their ages: until 40 years, between 41 and 70 and 71 or older. They were allocated in groups of time intervals: Group 1 (January 1971 to December 1980), Group 2 (January 1981 to December 1989) and Group 3 (January 1990 to December 1998).

The recommendations of the Japanese Gastric Cancer Association were followed.

The averages of each variable were analyzed as a whole, and in diverse groups of temporal (time) variations. Interrelationships between gender and age, and with tumor's location on gastric wall were also analysed.

To verify the independence of the variables were used Pearson's Chi-Square Test, and Chi-Square Partition. The comparison among the average ages in the different periods was done by the Analysis of Variance Test (F). The significance level to accept the null hypothesis was $P<5 \%$.

\section{RESULTS}

From January 1971 to December 1998, 1578 patients with GC were hospitalized. Among them, 1021 individuals were treated with gastric resection, corresponding to $64.7 \%$ of all patients.

Males were the majority of the cases (711), responsible for $69.6 \%$ of the total. The patient's distribution according to their gender, in the three periods, is displayed on Table 1. The statistical analysis of proportionality evolution between the genders during the 28 years showed an increase in number of women. The consequence, there was a clear decrease in the gender ratio in recent years. The average relationship between the male and female genders, pertaining to the whole study period, was 2.3.

TABLE 1 - Evolution in the proportion between genders of pacients suffering from gastric adenocarcinoma submitted to a gastrectomy at HCFMUSP (1971-1998)

\begin{tabular}{llllll}
\hline & $\mathbf{1 9 7 1 - 8 0}$ & $\mathbf{1 9 8 1 - 8 9}$ & $\mathbf{1 9 9 0 - 9 8}$ & TOTAL & \\
\hline Woman & 54 & 80 & $176^{*}$ & 310 & \\
& 26,3 & 26 & 34,6 & 30,4 & - percentages \\
Man & 151 & 228 & 332 & 711 & \\
& 73,7 & 74,0 & 65,4 & 69,6 & - percentages \\
Ratio & 2,8 & 2,8 & 1,8 & 2,3 & \\
\hline Total & 205 & 308 & 508 & 1021 &
\end{tabular}

The sample division in different age groups permitted analysis to determine in what age groups bigger significant changes occurred. There was an increase in the proportion of patients older than 70 years, and decrease between 41 and 70 years.

The average age was 59.7 with the youngest being 21 and the oldest 93 (median $=60$ ). An analysis of the disease occurrence in the distinct age groups displayed a predominance in the 6th and 7th decades (Figure 1).

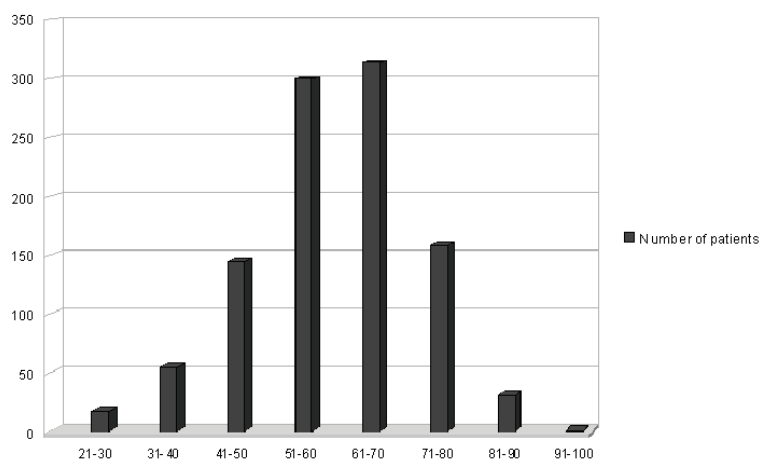

FIGURE 1 - analysis of the disease occurrence in the distinct age groups displayed a predominance in the 6th and 7 th decades.

\section{Relationship between the age and gender}

The age averages for each gender were calculated in years for the groups in the period included. The average men's age was 59.7, similar to the women's 59.8. In three periods happened an increase in age average for both genders. Only in the first period there was a difference between the gender's ages average.

The gender distribution in the three distinct age groups was analyzed. A statistical analysis of each age group demonstrated that in the group aged 41 to 70 there was a greater proportion of men.

In the analysis of each age group - seeking for variations in the gender proportions in periods, no statistical significant differences were observed.

\section{Relationship between age and location}

There was an attempt to establish a correlation of the different age groups with the tumor location in the gastric wall. Initially the patients of each group were studied throughout time period (1971 to 1998). The wasn't any relationship of the age groups and the tumor's location (Table 2). In temporal evolution, tumors that affected the reminiscent and all of the stomach (Table 3 ) were excluded. There was an increase in the number of tumors located in the proximal and middle stomach among patients aged 41 and 70 years. Among the ones with 71 years or older, there were differences among the different periods to the proportion of the tumor's locations in the gastric wall. There was an increment in the number in the middle third with a decrease on the distal.

TABLE 2 - Distribution by Gender and Age group of pacients submitted to a gastrectomy and the tumor's localization HCFMUSP (1971-1998)

\begin{tabular}{llllll}
\hline & & $<\mathbf{4 0}$ & $\mathbf{4 1 - 7 0}$ & $>\mathbf{7 1}$ & Total \\
\hline Localization & $\mathrm{L}$ & 39 & 408 & 101 & 548 \\
& & 54,2 & 53,7 & 53,2 & 53,3 \\
& $\mathrm{M}$ & 23 & 193 & 56 & 272 \\
& & 31,9 & 25,4 & 29,5 & 26,6 \\
& $\mathrm{U}$ & 8 & 91 & 18 & 117 \\
& & 11,1 & 12 & 9,5 & 11,5 \\
& \multirow{2}{*}{ Coto } & 1 & 46 & 9 & 56 \\
& & 1,4 & 6 & 4,7 & 5,5 \\
& \multirow{2}{*}{ Whole } & 1 & 21 & 6 & 28 \\
& & 1,4 & 2,8 & 3,6 & 2,7 \\
\hline Location $\mathbf{X}^{\wedge} \mathbf{2}=\mathbf{6 , 0 7}$ & $P=0,64$ & & &
\end{tabular}


TABLE 3 - Gastric cancer distribuition in different parts of the organ and its respective temporal evolution. The date refer to pacients submitted to a gastrectomy at HCFMUSP between the years of 1971 and 1998.

\begin{tabular}{|c|c|c|c|c|}
\hline Age groups & Location & 1971-80 & 1981-89 & $1990-98$ \\
\hline \multirow[t]{6}{*}{$<40$} & $\mathrm{~L}$ & 13 & 12 & 14 \\
\hline & & 76,5 & 60 & 42,4 \\
\hline & M & 3 & 7 & 13 \\
\hline & & 17,6 & 35 & 39,4 \\
\hline & $\mathrm{U}$ & 1 & 1 & 6 \\
\hline & & 5,9 & 5 & 18,2 \\
\hline \multirow[t]{6}{*}{$41-71$ years } & L & 123 & 116 & $169 *$ \\
\hline & & 74,1 & 51,3 & 56,3 \\
\hline & M & 28 & 85 & 80 \\
\hline & & 16,9 & 37,6 & 26,7 \\
\hline & $\mathrm{U}$ & 15 & 25 & 51 \\
\hline & & 9 & 11,1 & 17 \\
\hline \multirow[t]{6}{*}{$>71$ years } & L & 13 & 21 & $67 * *$ \\
\hline & & 92,9 & 51,2 & 55,8 \\
\hline & M & 1 & 13 & 42 \\
\hline & & 7,1 & 31,7 & 35 \\
\hline & $\mathrm{U}$ & 0 & 7 & 11 \\
\hline & & & 17,1 & 9,2 \\
\hline
\end{tabular}

( ) $=\%$

$\mathrm{L}=$ Distal third of the stomach $\mathrm{U}=$ Proximal third of the stomach

$\mathrm{M}=$ Stomach's average third

$<=40$ years: $X^{\wedge} 2=6,578 P=0,16$

41-70 years: $X^{\wedge} 2=30,351 P<0,0001 *$

$>=71$ years $\mathrm{X}^{\wedge} 2=9,833 P=0,04 * *$

It was compared the tumor's location in the gastric wall and the patient's average age (Table 4). There was no statistical significant difference among the average ages and the different locations.

TABLE 4 - Distribution of patients submitted to a gastrectomy according to its location and their respective average ages (HCFMUSP - 1971 to 1998)

\begin{tabular}{lllllll}
\hline & L & M & U & Coto & All & TOTAL \\
\hline $\begin{array}{l}\text { Average } \\
\text { Age }\end{array}$ & 59,5 & 60 & 58,5 & 61,4 & 62,7 & 59,7 \\
$\begin{array}{l}\text { D.P. } \\
\text { Total }\end{array}$ & 12,2 & 12,9 & 12,3 & 9,4 & 9,8 & 12,2 \\
\hline
\end{tabular}

$\mathrm{F}=1,04 / P=0,384$ / D.P. $=$ Standard Deviation

\section{Relationship between location and gender}

Table 5 displays the gender proportions in the five locations. There were significant differences for the locations of proximal third and stump, both more prevalent in males.

TABLE 5 - Patients distribution submitted to a gastrectomy according to the tumor's location in the stomach and the patient's gender (HCFMUSP - 1971 to 1998)

\begin{tabular}{cccccccc}
\hline & & L & M & U & Coto & All & TOTAL \\
\hline Gender & Female & 180 & 89 & 23 & 8 & 10 & 310 \\
& & 32,8 & 32,7 & 19,7 & 14,3 & 35,7 & \\
& \multirow{2}{*}{ Male } & 368 & 183 & $94^{*}$ & $48^{*}$ & 18 & 711 \\
& & 67,2 & 67,3 & 80,3 & 85,7 & 64,3 & \\
\hline
\end{tabular}

Sex: $\mathrm{X}=15,88$ and $P=0,003 *$

There was a separate study of the temporal evolution (evolution over time) between the gender ratios for each tumor location covering the whole period of time. Were excluded tumors located in the stump and the ones covering the whole stomach. There was a significant difference between the gender ratio for tumors affecting the distal stomach with an increase in number of women affected by the disease.

\section{DISCUSSION}

In addition to a decrease in the number of worldwide cases of GC, some changes in the epidemiological patterns have been displayed, as proportionally greater number of other individuals suffering from the disease, and greater incidence in women?.

Similarly to what has been demonstrated in the majority of previous studies, male patients were the majority in this study, representing $69.6 \%$ of all cases ${ }^{3}$. This male predominance usually occurs in the proportion of two men for every woman, similar to what was found here, being proportion men/women 2.3.

The study of the temporal trend of the gender proportion have shown an increase in the last years in the number of women suffering from the disease $(26,3 \%$ to $34,6 \%)$ of all the total patients that were submitted to surgeries at the HCFMUSP.

Other researchers had already confirmed this trend ${ }^{9}$. Kubo, et al. ${ }^{5}$ observed a decrease in the ratio men/women from 2.8 (between the years of 1939 and 1947) to 1.6 (between 1951 and 1968) in the United States.

This increase in the proportion of female patients among those affected by GC is not a consensus in the scientific literature.

In this study, the average age of those suffering from GC was 59,7 years, with a greater incidence in individuals aged 50 to $70(60 \%$ of the cases). There was here an increase in the proportion of patients over 70 years.

Another data is the significant number of patients with more than 70 years submitted to a surgical resection (18\%). This number is superior than that one obtained by Oohara, et al. ${ }^{7}$ at Tokyo's University, were patients over 70 years were responsible for 11,8\% of all cases between 1958 and 1980 .

Nevertheless, western studies have shown a greater number of patients with more than 70 years and even half of the than with more than this age. In the present study, during the years of 1971 to 1998 , it was observed an increase in the average age of patients submitted to a gastric resection due to GC (55.2 to 60.5 years).

In this study the ratio men/women was different for the three age groups. For patients up to 40 years this ratio was 1.6; a similar ratio was found in patients with more than 70 years. Nevertheless for patients aged 41 to 70 , this ratio increased to 2.6 .

There is a hypothesis that says that this variation could be due to difference in calorie intake between the genders in stages of their lives, and the exposure to potential carcinogens during their childhood.

The study of the ratios between genders during all these years - despite differences in the general population -, do not permit to determine in what age group is greater intensity.

GC shows different ratios between genders according to its location in the stomach wall. Flamant, el al. ${ }^{1}$ found 5.1 and 2.1, when compared the proximal third and other 
locations. These authors stated that this variation was due to alcoholic beverages and cigarettes which have a greater impact in the stomach's cardiac region. Hansson, et al. ${ }^{2}$ in Sweden observed that this ratio was 4.1 to tumors of the upper third.

This study had a ratio men/women of two for tumors located in the distal third in comparison to a ratio of 4.1 for tumors located in the proximal third. It is important to highlight the ratio found for $\mathrm{GC}$ in the remaining portions of the stomach (around six).

It also important to mention the trend favoring a change in the gender ratio, when it is independently analyzed for each tumor location and it was significant only pertaining to the distal third location. In all of the other locations it did not reach a significant statistical level.

In this study it was not observes differences among the average ages of patients in the three main locations studied (distal, middle and proximal third) with average ages of 58,9,59,4 and 58,4, respectively). Maehara, et al. ${ }^{6}$ also did not note any difference in the average ages of patients with proximal tumors and those located in other areas of the stomach.

Nevertheless, Rios-Castellanos, et al. ${ }^{8}$ analyzing patients between 1960-64 and 1984-88, not only observed an increase in the average age of the patients with GC in all stomach's locations, but also found differences among them. The patients suffering from tumors on the proximal third were on average five years younger than those that had tumors located in antro-duodenal portion or pyloric antrum.

Among the patients aged 41 to 70 years and with more than 70 years a statistical difference was obtained for tumors located in the middle and proximal thirds with a decrease in distal ones. Oohara, et al. ${ }^{7}$ in a study of patients over 70 found the following tumor distribution: distal third $50,7 \%$, middle $33,5 \%$ and proximal $15,8 \%$ most similar to the ones here obtained of $57,7 \%, 32 \%$ and $10,3 \%$ respectively.

\section{CONCLUSIONS}

a) Occurred modifications in the ratio between genders: greater number of women and an increase in the number of male patients in the age group between 41 and 70 years; $b$ ) it was proved the greater number of occurrences in patients over 70 years of age; $c$ ) there was a greater increase in the male predominance in the tumors located in the stomach's proximal third.

Jacob CE, Bresciani C, Gama-Rodrigues JJ, Yagi OK, Mucerino D, Zilberstein B, Cecconello I. Comportamento do câncer gástrico na população brasileira. ABCD Arq Bras Cir Dig 2009;22(1):29-32

RESUMO - Racional - O câncer gástrico é afecção predominantemente masculina. Para cada mulher há dois homens, mas tem ocorrido aumento de casos em mulheres nas últimas décadas. O Brasil é pobre em dados sobre esse tema. Objetivo - Verificar se no Brasil em relação ao câncer gástrico ocorreu: a) mudança na relação entre os sexos; b) aumento no número de pacientes com mais de 70 anos portadores da doença; c) alteração na relação gênero e média de idade nas variadas localizações do tumor. Metodos - Prontuários de pacientes com adenocarcinoma do estômago 1971 e 1998 foram obtidos no Hospital das Clínicas da Universidade de São Paulo, Brasil com os seguintes critérios de exclusão: pacientes portadores de doença não epitelial; adenocarcinoma de metaplasia intestinal no esôfago distal invadindo cárdia e pacientes submetidos à ressecção gástrica durante os últimos cinco anos anteriores ao período de estudo. Foram divididos em intervalos de 10 anos e também em três grupos de acordo com suas idades e intervalo de tempo. Foram analisadas inter-relações entre sexo e idade, e a localização do tumor em relação à parte anatômica do órgão. Resultados - De 1971 a 1998, 1578 pacientes foram hospitalizados com câncer do estômago. Dentre eles, 1021 foram tratados com ressecção gástrica (64,7\%). Houve aumento na proporção de pacientes com mais de 70 anos e diminuição entre a faixa de 41 a 70 . Não houve diferença estatística entre a idade e as várias localizações. Houve diferença significante favorecendo a localização proximal e coto gástrico, ambas mais prevalentes nos homens. Conclusões - a) Ocorreram modificações na relação entre os sexos: maior número de mulheres e aumento no número de homens na idade entre 41 e 70; b) demonstrou-se aumento no número de pacientes com mais de 70 anos; c) houve aumento da prevalência de tumores na parte proximal do estômago e maior nos homens.

DESCRITORES - Neoplasia gástrica. Epidemiologia. Cirurgia.

\section{REFERENCES}

1. Flamant R, Lasserre O, Lazar P, Leguerinais J, Denoix P, Schwartz D. Differences in sex ratio according to cancer site and possible relationship with use of tobacco and alcohol. review of 65,000 CASES. J Natl Cancer Inst. 1964 Jun;32:1309-16.

2. Hansson LE, Sparén P, Nyrén O. Increasing incidence of carcinoma of the gastric cardia in Sweden from 1970 to 1985. Br J Surg. 1993 Mar;80(3):374-7.

3. Jacob CE, Gama-Rodrigues J, Bresciani CJ, Zilberstein B, Proscurshim I, Iriya $\mathrm{K}$, Alves VA, Cecconello I. Trends in tumor location in gastric carcinoma over a 28-year period. Hepatogastroenterology. 2007 Jun;54(76):1297-301.

4. Jacob CE, Gama-Rodrigues JJ, Irya K, Bresciani CJC, Zilberstein B, Martins BC, Cecconello I. Câncer gástrico precoce: complicações e mortalidade após gastrectomia e linfadenectomia regrada - Experiência com 178 casos em uma instituição. ABCD 19(4)

5. Kubo T, Imai T. Intestinal metaplasia of gastric mucosa in autopsy materials in Hiroshima and Yamaguchi districts. Gann. 1971 Feb;62(1):49-53.

6. Maehara Y, Moriguchi S, Kakeji Y, Kohnoe S, Korenaga D, Haraguchi M, Sugimachi K. Pertinent risk factors and gastric carcinoma with synchronous peritoneal dissemination or liver metastasis. Surgery. 1991 Nov;110(5):820-3.
7. Oohara T, Johjima Y, Yamamoto O, Tohma H, Kondo Y. Gastric cancer in patients above 70 years of age. World J Surg. 1984 Jun;8(3):315-20.

8. Rios-Castellanos E, Sitas F, Shepherd NA, Jewell DP. Changing pattern of gastric cancer in Oxfordshire. Gut. 1992 Oct;33(10):1312-7.

9. Steevens J, Botterweck AA, Dirx MJ, van den Brandt PA, Schouten LJ. Trends in incidence of oesophageal and stomach cancer subtypes in Europe. Eur J Gastroenterol Hepatol. 2009 May 26

Fonte de financiamento: não há Conflito de interesse: não há Recebido para publicação: 16/07/2008 Aceito para publicação: 22/12/2009 